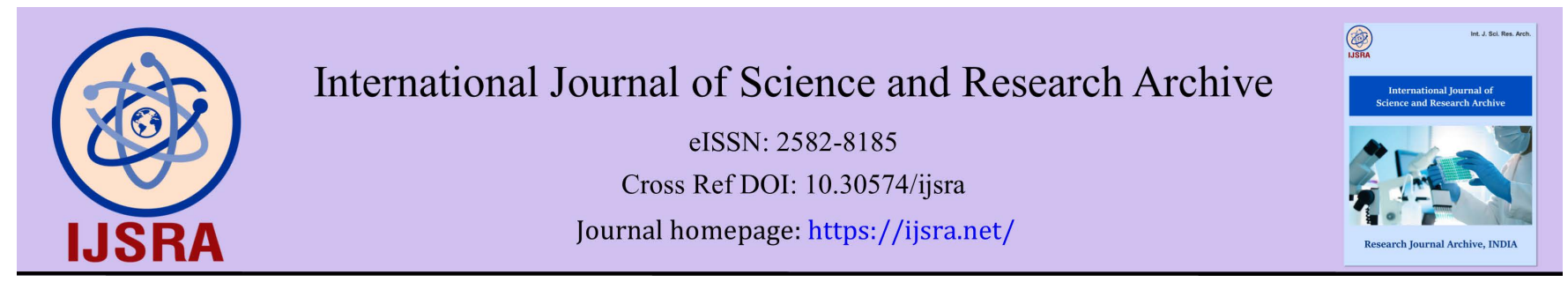

(RESEARCH ARTICLE)

\title{
Application of Riau local entomophatogenic fungi Beauveria bassiana toward brown planthopper pest and production of rice
}

\author{
Hapsoh, Desita Salbiah *, Isna Rahma Dini, and Widia Sari \\ Department of Agrotechnology, Faculty of Agriculture, Universitas Riau, Pekanbaru, Indonesia.
}

International Journal of Science and Research Archive, 2021, 03(01), 124-129

Publication history: Received on 30 May 2021; revised on 04 August 2021; accepted on 06 August 2021

Article DOI: https://doi.org/10.30574/ijsra.2021.3.1.0092

\begin{abstract}
The decrease in rice production can be caused by pests that can damage the quality and quantity. Pests that always attack rice plants are Brown planthopper. The BPH causes several effects, namely hopperburn, as a virus vector and can cause crop failure. The control of BPHs by farmers to date is by using synthetic pesticides. The use of synthetic pesticides can cause residues, resistance, resurgence, and the destruction of natural enemies. The use of synthetic insecticides can be minimized by using environmentally friendly and sustainable control alternatives, namely by using the local entomopathogenic fungi B. bassiana. This study aims to determine the effect of the application of local Riau B. bassiana on BPH and rice production.The research was conducted at the Laboratory of Plant Pests and Experimental Gardens, Faculty of Agriculture, Riau University from April to July 2020. The research was designed a completely randomized design with five treatments local entomopathogenic fungi concentrations B. bassiana 0 g.l ${ }^{-1}$ water, 10 g.l ${ }^{-1}$ water, 20 g.l${ }^{1}$ water, 30 g.l ${ }^{-1}$ water, 40 g.l ${ }^{-1}$ water and four replications, in order to obtain 20 experimental units. The results showed

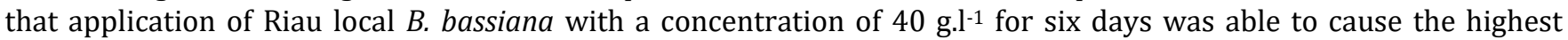
mortality of $92.5 \%$. The higher the concentration of Riau local B. bassiana, the lower the attack intensity. The attack of brown planthopper nymphs affects the quality of rice production, but did not affect the quantity of rice production.
\end{abstract}

Keywords: Beauveria bassiana; Local entomophatogenic fungi; Brown planthopper; Rice production

\section{Introduction}

Rice plant is a food crop commodity that produces rice. 95\% of the Indonesian population uses rice as a staple food because it is able to meet $63 \%$ of the total energy adequacy and $37 \%$ of protein. Domestic demand for rice continues to increase in line with the increase in population and high levels of consumption. According to the Riau Province Central Bureau of Statistics [1], Riau Province in 2018 was able to produce rice production of 266,375 tons and decreased by $13.33 \%$ in 2019 to 230,873 tons. The decline in rice production causes the demand for rice in Riau Province to increase. Thus, increasing rice production is a priority in agricultural development.

The decrease in rice production can be caused by pests that can damage the quality and quantity. Pests that always attack rice plants are Brown planthopper (BPH). This pest is the most dangerous pest compared to other pests because it is easy to adapt to a new environment. The BPH causes several effects on rice plants, namely hopperburn, as a virus vector for grass dwarf and hollow dwarf diseases and can cause crop failure [2].

Rice production can be optimized by controlling BPH pests. The control of BPHs by farmers to date is by using synthetic pesticides. The use of synthetic pesticides can cause residues, resistance, resurgence, and the destruction of natural enemies. The use of synthetic insecticides can be minimized by using environmentally friendly and sustainable control alternatives, namely by using the local entomopathogenic fungi $B$. bassiana. The use of entomopathogenic fungi in pest

\footnotetext{
* Corresponding author: Desita Salbiah

Department of Agrotechnology, Faculty of Agriculture, Universitas Riau, Riau, Indonesia., Pekanbaru, Indonesia.

Copyright $(2021$ Author(s) retain the copyright of this article. This article is published under the terms of the Creative Commons Attribution Liscense 4.0.
} 
control has potential because it has a high reproductive capacity, short life cycle, is relatively safe, selective, relatively easy to produce, and is very unlikely to cause pest resistance [3]. According to Trizelia et al. [4], the use of local isolates is better because local entomopathogenic fungi is considered easy to adapt to the local ecosystem so that it will not disturb the ecological balance.

Riau local B. bassiana has been shown to cause mortality Leptocorisa oratorius $\mathrm{F} 97.5 \%$ for 12 days at a concentration

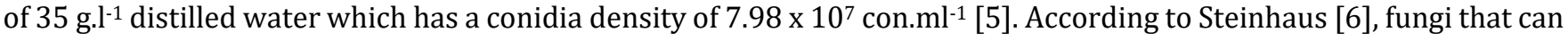
be categorized as bioinsecticides are fungi that successfully control insects with a mortality of $72 \%$ - $95 \%$.

\section{Material and methods}

\subsection{Materials}

The rice seeds used were PB-42 rice seeds obtained from the Riau Province Agricultural Technology Research Center, used for application plants and BPH nymph breeding. Imago BPH is taken from a rice plant area in Jayapura Village, Bunga Raya District, Siak Regency, Riau Province which is used for BPH pest breeding which is applied using the Riau local B. bassiana. Land used for provision Riau local B. bassiana comes from the rhizosphere of rice plants in Langsat Permai Village, Bunga Raya District, Siak Regency, Riau Province.

\subsection{Instruments}

The research was carried out at the Plant Pest Laboratory and Experimental Garden, Department of Agrotechnology, University of Riau from April to July 2020. The research was carried out experimentally using a completely randomized design consisting of 5 treatments and 4 replications, obtained 20 experimental units with each treatment being an application. concentration of Riau local entomopathogenic fungi $B$. bassiana 0 g.l-1 water, $10 \mathrm{~g} . l^{-1}$ water, $20 \mathrm{~g} . l^{-1}$ water,

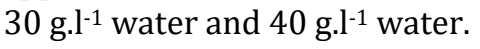

\subsection{Provision of Riau local B. bassiana}

Isolation of the B. bassiana was carried out using the insect bait method using fifth instar Tenebrio molitor larvae. $T$. molitor suspected of being infected with the B. bassiana was transferred to filter paper and incubated for seven days. The $B$. bassiana were isolated in PDA media and incubated for seven days. Identification of the Riau local B. bassiana was carried out macroscopically and microscopically based on its morphological shape using a book written by Barnett and Hunter [7].

The Riau local isolate B. bassiana growing on PDA media was isolated on broken maize medium and incubated for five days. The starter B. bassiana broken corn was weighed according to the treatment, namely $10 \mathrm{~g}, 20 \mathrm{~g}$, and $30 \mathrm{~g}$, and 40 $\mathrm{g}$ and each was mixed with $1000 \mathrm{ml}$ of water then stirred and filtered. The suspension is put in a bottle and shaker for 24 hours. The suspension is then carried out dilution with a ratio of one $\mathrm{ml}$ of suspension and nine $\mathrm{ml}$ of water to a dilution of $10^{-7}$. Conidia were seen using a haemocytometer under a microscope and conidia density was counted by handcounter. Conidia density is calculated by the formula:

$$
J=\frac{\mathrm{t} \times \mathrm{d}}{0.25 \times \mathrm{n}} \times 10^{6}
$$

Where,

J : The density of conidia in $1 \mathrm{~g}$ of media

$\mathrm{t} \quad:$ The density of the conidia in all calculated squares

n : : The number of squares counted

$\mathrm{d} \quad:$ : Dilution factor if to should diluted $(\mathrm{d}=1$ means no dilution; $\mathrm{d}=10$ means dilution $1: 10)$

$0.25 \quad$ : Constants

\subsection{Application}

The application was carried out by spraying it evenly on each experimental unit to the rice plants and fifth instar BPH nymphs. Applications are carried out 24 hours after infestation of BPH nymphs at 17.00 WIB. 


\subsection{Data Analysis}

The daily mortality data obtained were displayed in graphical form and analyzed descriptively, while the attack intensity data and rice production data were statistically analyzed using analysis of variance. The results of the analysis of variance that showed significant differences were further tested with Duncan's New Multiple Range Test (DNMRT) at the $5 \%$ level.

\section{Results}

\subsection{Daily Mortality (\%)}

The results of daily mortality of BPH nymphs with different applications of Riau local B. bassiana showed fluctuations in the mortality of BPH nymphs. Daily mortality fluctuations can be seen in Figure 1. Figure 1 shows that on the first day there was death of BPH nymphs on application of Riau local B. bassiana local $40 \mathrm{~g}^{-1}{ }^{-1}$ water, while other concentrations did not show any death.

\subsection{Attack intensity (\%)}

Application of Riau local B. bassiana showed results that significant effect the intensity of attack by BPH nymphs. The intensity of BPH nymph attacks on rice plants can be seen in Table 1.

\subsection{Rice Production}

Application of Riau local B. bassiana to BPH in rice showed different effects of rice production. The application of local Riau B. bassiana had a significant effect on the percentage of pithy grain and the percentage of empty grain, but had no significant effect on panicle length and weight of 1000 seeds, this can be seen in Table 2 .

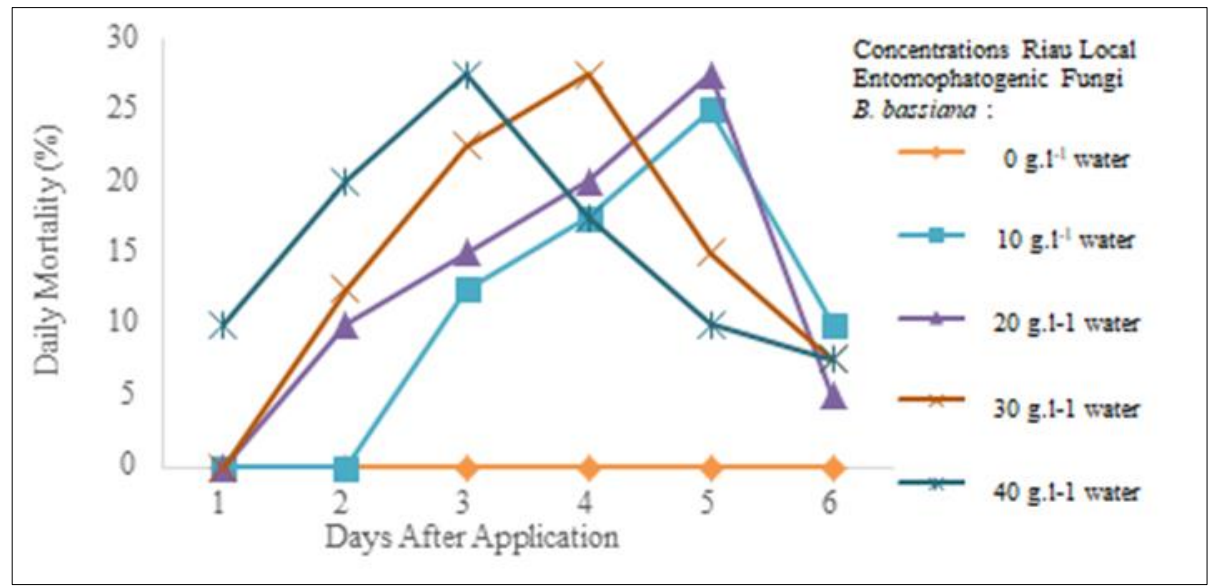

Figure 1 Daily mortality fluctuations of BPH nymphs after application of Riau local B. bassiana

Table 1 Attack intensity of BPH nymph on rice plants after application of Riau local B. bassiana

\begin{tabular}{|c|c|}
\hline Concentrations of Riau local B. bassiana (Conidia Density) & Attack Intensity (\%) \\
\hline 0 g.l-1 water $\left(0,00 \times 10^{8}\right.$ con.ml- $\left.{ }^{-1}\right)$ & 29,92 a \\
\hline 10 g. $\mathrm{l}^{-1}$ water $\left(2,73 \times 10^{8}\right.$ con.ml-1 $)$ & $18,65 \mathrm{~b}$ \\
\hline 20 g.l $\mathrm{l}^{-1}$ water $\left(3,15 \times 10^{8}\right.$ con.ml-1 $)$ & $15,53 \mathrm{bc}$ \\
\hline 30 g.l $\mathrm{l}^{-1}$ water $\left(3,64 \times 10^{8}\right.$ con.ml-1 $)$ & $13,12 \mathrm{~cd}$ \\
\hline 40 g.l $\mathrm{l}^{-1}$ water $\left(4,27 \times 10^{8}\right.$ con.ml-1 $)$ & 10.58 e \\
\hline
\end{tabular}

The numbers in the line followed by lowercase letters that are not the same are significantly different according to the DNMRT test at the 5\% level. 
Table 2 Rice production after application of Riau local B. bassiana

\begin{tabular}{|c|c|c|c|}
\hline $\begin{array}{l}\text { Concentrations of Riau local } B \text {. } \\
\text { bassiana (Conidia Density) }\end{array}$ & $\begin{array}{c}\text { Panicle } \\
\text { Length }(\mathrm{cm})\end{array}$ & $\begin{array}{c}\text { Percentage of } \\
\text { Pithy Grains (\%) }\end{array}$ & $\begin{array}{l}1000 \text { Seeds } \\
\text { Weight (g) }\end{array}$ \\
\hline 0 g.l $\mathrm{l}^{-1}$ water $\left(0,00 \times 10^{8}\right.$ con.ml- $\left.{ }^{-1}\right)$ & $26,50 \mathrm{a}$ & $61,73 \mathrm{c}$ & $19,35 \mathrm{a}$ \\
\hline 10 g.l-1 water $\left(2,73 \times 10^{8}\right.$ con.ml-1) & $26,00 \mathrm{a}$ & $79,75 \mathrm{~b}$ & $19,60 \mathrm{a}$ \\
\hline 20 g..$^{-1}$ water $\left(3,15 \times 10^{8}\right.$ con.ml $\left.l^{-1}\right)$ & $26,00 \mathrm{a}$ & $88,14 a$ & $19,95 \mathrm{a}$ \\
\hline 30 g.l -1 $^{-1}$ ater $\left(3,64 \times 10^{8}\right.$ con.ml-1) & $26,95 \mathrm{a}$ & $88,56 a$ & $20,10 \mathrm{a}$ \\
\hline 40 g. $\mathrm{l}^{-1}$ water $\left(4,27 \times 10^{8}\right.$ con.ml-1) & $27,75 \mathrm{a}$ & $91,81 \mathrm{a}$ & $20,20 \mathrm{a}$ \\
\hline
\end{tabular}

The numbers in the line followed by lowercase letters that are not the same are significantly different according to the DNMRT test at the $5 \%$ level.

\section{Discussion}

\subsection{Daily Mortality (\%)}

All local concentrations of Riau local B. bassiana experienced an increase in daily mortality. The application of Riau local B. bassiana with a concentration of $40 \mathrm{g.l}^{-1}$ of water first reached the peak daily mortality, namely on the third day of $27.5 \%$ compared to the concentration of Riau local B. bassiana of 30 g. $\mathrm{l}^{-1}$ water, 20 g. $\mathrm{l}^{-1}$ water and 10 g. $\mathrm{l}^{-1}$ water. This is

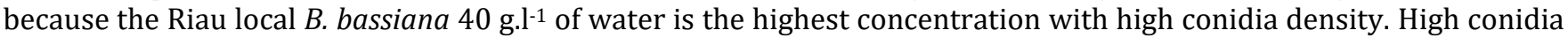
density causes high mortality, this is because the beauvericin toxin produced can infect maximally. This is in accordance with the opinion of Destiyanti et al. [8] that the higher the conidia density, the higher the mortality rate, thus allowing conidia contact with the insect body in large numbers. Trizelia and Nurdin [9] stated that the amount of beauvericin toxin produced by the fungus depends on the number of conidia that are infected with the target insect.

The application of Riau local B. bassiana at concentrations of 20 g.l-1 water and 10 g.l-1 water reached the peak of BPH nymph mortality on the fifth day after application, namely $27.5 \%$ and $25 \%$, respectively. Both concentrations had a longer time to reach the peak of BPH nymph mortality compared to concentrations of 30 g. $\mathrm{l}^{-1}$ water and 40 g. $\mathrm{l}^{-1}$ water. This is presumably because the local B. bassiana has a relatively low conidia density, so that the beauvericin toxin produced is slightly resulting in a longer peak daily mortality. This is in accordance with the opinion of Salbiah and Rumi'an [5] that the low conidia density resulted in fewer conidia germinating so that the chances of $B$. bassiana in killing insects were also lower.

Application of concentrations Riau local concentrations B. bassiana decreased the daily mortality percentage after experiencing peak daily mortality of BPH nymphs. This happened because Riau local B. bassiana had developed in the body of BPH nymphs to produce beauvericin toxin and succeeded in infecting BPH nymphs causing death, resulting in high daily mortality. The high daily mortality that reached the peak of mortality of BPH nymphs caused many BPH nymphs to die, so that on the next day there was a decrease in daily mortality due to the fewer number of available BPH nymphs.

\subsection{Attack Intensity (\%)}

Table 1 shows that the application of Riau local B. bassiana to BPH nymphs on rice plants with a concentration of 40 g.l${ }^{1}$ caused the lowest attack intensity of BPH nymphs at $10.58 \%$ and was significantly different from other concentrations. This is because the local Riau B. bassiana 40 g.l-1 water is the highest concentration with the highest conidia density, which is $4.27 \times 108$ con.ml- ${ }^{-1}$. The highest concentration applied caused the BPH nymphs to experience the highest mortality as can be seen in the daily mortality of BPH nymphs in Figure 1. The fewer BPH nymphs found in rice plants, the lower the attack intensity of BPH nymphs. This is in accordance with the opinion of Ramadhani and Herawati [10] that $B$. bassiana can reduce the population of pests that will attack cabbage plants and cause a low average intensity of pest attacks. Meanwhile, cabbage plants that are not applied to B. bassiana do not get protection so that pests can easily attack plants. 
The concentration of local Riau B. bassiana 0 g.l-1 water caused the highest BPH nymph attack intensity, which was $29.92 \%$, which was significantly different from other concentrations. The percentage of this attack is still categorized as a light attack level. This is in accordance with the exposure of the Directorate of Food Crop Protection [11] that the intensity of BPH attacks $<25 \%$ is categorized as very light intensity, $>25-50 \%$ is categorized as mild intensity, $>51-75 \%$ is categorized as moderate intensity and $>75 \%$ is categorized as severe attack intensity.

The damage caused by BPH is that the rice plant dries up because BPH sucks the liquid in the rice plant transport network. Symptoms of BPH attack on the clump can be seen from the yellowing of the leaves, then the plant dries quickly like a burn. This is in accordance with the declare of the Agricultural Research and Development Agency [12] that BPH pests can cause mild to severe damage in almost all phases of growth starting from the seedling phase, tiller to the ripening phase of milk. Symptoms due to WBC attack are yellowing of the leaves, the plant dries up quickly like burning, which is called hopperburn symptoms. The hopperburn symptom shows a pattern of BPH spread starting from one point and spreading in all directions in a circular shape.

\subsection{Rice Production}

From the analysis of panicle length (Table 2), it was shown that the application of local Riau B. bassiana in controlling BPH nymphs had no significant effect on panicle length and 1000 seed weights of rice plants. This indicates that local $B$. bassiana does not affect rice production in quantity. Panicle length is a parameter that determines the high and low production of a line or variety, because the longer the panicle, the greater the chance of increasing the number of grain in one rice plant [13].

However, the application of local Riau B. bassiana in controlling BPH nymphs had an effect on the percentage of pithy grain. The concentration of Riau local B. bassiana 40 g.l $\mathrm{l}^{-1}$ of water was able to cause the highest percentage of pithy grain that was $91.81 \%$ which was not significantly different with concentrations of 30 g.l-1 water and 20 g.l-1 water, but significantly different with a concentration of $10{\mathrm{~g} . l^{-1}}^{-1}$ water and 0 g.l-1 of water. This was presumably because the concentrations of $40 \mathrm{~g} . \mathrm{l}^{-1}$ water, $30 \mathrm{~g} . \mathrm{l}^{-1}$ water and $20 \mathrm{~g} . \mathrm{l}^{-1}$ water had conidia density which tended to be high so that they were able to control BPH nymphs. The fewer BPH nymphs found in the rice clump, the better the quality of the grain produced. This is in accordance with the opinion of Darmadi and Alawiyah [14] that the quality of rice plants is influenced by the number of filled grains and at least empty grains. The quality of the grain can be affected by BPH because high $\mathrm{BPH}$ attacks cause a lot of empty grain, BPH causes rice plants to fall and light intensity decreases, dry leaves cause starch in the grains to decrease.

\section{Conclusion}

Application of Riau local B. bassiana with a concentration of 40 g.l-1 for six days was able to cause the highest mortality of $92.5 \%$. The higher the concentration of Riau local B. bassiana, the lower the attack intensity. The attack of brown planthopper nymphs affects the quality of rice production, but did not affect the quantity of rice production.

\section{Compliance with ethical standards}

\section{Acknowledgments}

The author would like to thank the Directorate of Research and Community Service, Ministry of Research and Higher Education of the Republic of Indonesia (KEMRISTEKDIKTI) (Contract number: 393/UN.19.5.1.3/PT 01.03/2020) for funding this research. This research is part of the Basic Research grant.

\section{Disclosure of conflict of interest}

All authors declare there is no conflict of interest in this paper.

\section{References}

[1] Riau Province Central Bureau of Statistics. Area of Rice Harvest and Production in Riau Province 2019. Central Statistics Agency of Riau Province. Pekanbaru. 2020.

[2] Rahmini. Rice Brown Planthopper Pests and How to Control Them. Sukamandi Rice Research Center. West Java. 2014. 
[3] Prayogo Y. Efforts to maintain the effectiveness of entomopathogenic fungi to control food crop pests. Journal of Agricultural Research and Development. 2006; 25(2): 47-54.

[4] Trizelia N, et al. Diversity of entomopathogenic fungi in the rhizosphere of various vegetable crops. Proceedings of the National Seminar on the Indonesian Biodiversity Society. 2015; 1: 998-1004.

[5] Salbiah D, Rumi'an. The local entomopathogenic fungi Beauveria bassiana Vuillemin as a control agent for the stink bug (Leptocorisa oratorius Fabricius) in lowland rice plants. West PTN National BKS Seminar. 2014; 703709.

[6] Steinhaus EA. Principles of Insect Phatology. McGRaw Hill Book Company. New York. 1969.

[7] Barnett HL, Hunterr. Ilustrated Genera of Imperfect Fungi Third Edition. Burgess Publishing Company. Minneapolis. Minnesota. 1972.

[8] Destiyanti Y, et al. Effectiveness of several entomopathogenic fungi to control subterranean termites Captotermes gestrio Wesmann (Isoptera: Rhinotermidae) by contact and bait method. Journal Tropical Wood Science and Technology. 2007; 5(2): 68-77.

[9] Trizelia, Nurdin. Increased Physiological Persistence and its virulence against Crocidolomia pavonana $\mathrm{F}$ (Lepidoptera; Pyralidae). [Thesis]. Bogor Agricultural Institute. Bogor. 2008.

[10] Ramadhani VA, MM Herawati. Potential concentration of Beauveria bassiana as a biological agent in the cultivation of cabbage (Brassica oleracea L.). Proceedings of the 2019 National Scientific Work Concert. 2019; 9095.

[11] Directorate of Food Crop Protection. Brown Planthopper and Control Efforts. Directorate of Food Crop Protection. Jakarta. 2011.

[12] Agricultural Research and Development Agency. High Rainfall Beware of Explosion of Brown Planthoppers. Ministry of Agriculture. Jakarta. 2016.

[13] Untung K. Institutionalizing the concept of integrated pest control in Indonesia. Indonesian Journal of Plant Protection. 2000; 6(1): 1-8.

[14] Darmadi D, T Alawiyah. Responses of several rice varieties (Oryza sativa L.) to the brown planthopper (Nilaparvata lugens Stall) Karawang Colony. Journal Agriculture. 2018; 29(2): 73-81. 